\title{
Exploring Recruitment and Selection Practices of Ghanaian Organisations
}

\author{
Gilbert Ansoglenang \\ Office of the Principal, University for Development Studies, Navrongo Campus, Ghana \\ E-mail: $\underline{\text { ansogle68@yahoo.com }}$
}

\begin{abstract}
Although Strategic Human Resource Management (SHRM) has emerged as the new approach to human capital management, operational level Human Resource Management (HRM) activities (traditional personnel functions) remain crucial when linking business strategy with HRM. This paper is inspired by the contribution of selection and recruitment practices in managing the global talent war, particularly in less developed economies. It is based on a multiple casestudy research into employee recruitment and selection techniques within five case-study firms located in Tema, Kumasi and Accra. The paper draws on in-depth face-to-face interviews and documents to explore the various recruitment and selection practices utilised by Ghanaian firms. The findings suggest more commonalities in the utilisation of the following employee recruitment sources - for example, newspaper advertisement, campus recruitment, employee referrals, direct applications and unsolicited applications among all case-study organisations and a slight variation in the utilisation of selection techniques such as: psychometric testing or aptitude testing, the use of assessment centres and employee referrals due to differences in employees' categories and industry types. Though internet-based recruitment is growing significantly among organisations, yet the evidence in this paper rather demonstrate limited growing visibility towards internet-based or social media recruitment among Ghanaian organisations. This paper set out a rationale for utilising multiple case-study design in Human Resource Management research in under-researched contexts.
\end{abstract}

Keywords: recruitment sources, selection techniques, multiple case-study research, Ghana

DOI: $10.7176 / \mathrm{EJBM} / 12-12-02$

Publication date: April $30^{\text {th }} 2020$

\section{Introduction}

The Strategic Human Resource Management (SHRM) domain has evolved over the last few decades yet remains a contentious Human Resource Management (HRM) theory (Boxall, 2018). Contributing to the ongoing SHRM debate, Paauwe and Boselie (2003) distinguished between HRM 'best-fit' and 'best' practice in an attempt to examine how HRM adds value to organisations. While 'best practice recognises the widespread success of certain HRM practices, 'best-fit' epitomize the relevant effect of contextual or related factors (see Paauwe \& Boselie, 2003). Although SHRM has emerged as the new approach to human capital management, operational level HRM activities (traditional personnel functions) remain crucial when linking business strategy with HRM (Boxall, 2018). Recruitment and selection remain one of the oldest HRM function and serve as the most important managerial tool for attracting qualified and talented employees (Brandao et al., 2018) and with a shared rationality of maximising both person-job fit and person-organisation fit outcomes (Acikgoz, 2018; Rodgers et al., 2013). Hiring an individual with potential positively impact on the organisation and is recognised as the principal objective of any recruitment and selection process (Barber, 1998). Importantly, while employee staffing strategies have become an important prerequisite for successful implementation of business strategies (Collings et al., 2007), the cost and direct impact associated with early employee turnover or exit in recent times has spawned much organisational attention on employee recruitment and selection (Ma \& Allen, 2009; Morse \& Popovich, 2009). Yet, recruitment and selection has received limited exploratory research attention among HRM practitioners and researchers alike in sub-Saharan Africa (Ayentimi, Burgess, \& Dayaram, 2018; Azungah, Michailova, \& Hutchings, 2018). This paper thus addresses this important knowledge and research gap by drawing on multiple case-study research evidence within five Ghanaian firms based in Accra, Kumasi and Tema. The paper is fundamentally grounded in multiple case-study research design in exploring employee recruitment and selection techniques of Ghanaian firms through in-depth face-to-face interviews and document analysis. The HRM literature acknowledge the ultimate contribution and the increasing importance of employee recruitment and selection practices to organisational competitiveness and talent retention (Russell \& Brannan, 2016; Ouirdi et al., 2016a), thus the paper aims to contribute to the recruitment and selection literature by shedding new insight into the various recruitment and selections techniques common in Ghanaian firms. The paper is inspired by the contribution of selection and recruitment practices to the global talent war among firms, particularly, firms operating in less developed host-countries characterised with skilled labour shortages (Ayentimi et al., 2018; Posthumus et al., 2016). Arguing through both the resource-based view of the firm and human capital theory, employee recruitment and selection function is a prerequisite for achieving a sustained competitive edge (Ouirdi et al., 2016b; Ma \& Allen, 2009; Piotrowski \& Armstrong, 2006). Human capital is exemplified in the productive potential of employee experience, attitude, knowledge and their intelligence (Brindusoiua, 2013). Accordingly, it is important to have an effective and efficient recruitment and selection strategy to ensure the 
organisation have the needed employees with the right attributes, knowledge and skills (Ouirdi et al., 2016b; Brindusoiua, 2013).

Recruitment and selection researchers have conceptualised recruitment sources into formal and informal or in other words, personal and impersonal sources (Acikgoz, 2018; Ma \& Allen, 2009; Breaugh, 2008). While formal recruitment sources denote the use of newspaper advertisements, campus recruitment, job fairs, employment agencies, informal recruitment sources acknowledge the use of employee referrals through family members, friends and close relatives (Tangaa \& Maphosa, 2018; McManus \& Ferguson, 2003; Zottoli \& Wanous, 2000). Despite the dominance of these traditional recruitment sources, online recruitment is currently experiencing a growing trend due to its associated benefits of transparency, quick feedback (automatic response services) and cost-effectiveness (Thanassoulis et al., 2018; Herdonson, 2018; Brandao et al., 2018). Online recruitment corresponds with social media recruitment platforms such as: Twitter, LinkedIn, Facebook, online job boards, company's websites etc. (Acikgoz, 2018). These social media technologies create the platform for firms to post job adverts, pre-screen applicants and provide feedback to potential applicants (Ouirdi et al., 2016a), and interview applicants via video-conferencing (Brandao et al., 2018; Bartram, 2000). In fact, social media technologies lend itself to recruitment and are recognised as a source of connection between job seekers and the company (McFarland \& Polyhart, 2015). However, it is fascinating to note that while online recruitment platforms are common in advanced economies, they are less utilised in less developed economies, particularly in subSaharan Africa owing to technological constraints. It can be argued that as access to technological infrastructure improves in less developed economies, digitally enabled recruitment platforms will assume a dominant position. Even though there are several recruitment sources available to potential employers, Breaugh and Starke (2000) found newspaper advertisements, employment agencies, direct application, employee referrals and campus recruitment as the commonly used recruitment sources among employers. Elliott (2001) found insider referrals to constitute a third source of new recruitments in many organisations in the United States and most often associated with informal jobs compared to formal jobs. Whereas, Gong (2003) maintained that firms staffing decisions have critical performance outcomes, Ahmad and Schroeder (2003) argued that employee staffing with a focus on attitude, behaviour and technical capabilities in addition to employee fit with organisational culture have the potential to enhance and sustain organisational performance.

\section{Recruitment and Selection: Towards a Convergence}

Recruitment and selection are multi-step processes that aim to select a skilled and qualified candidate. Barber (1998, p.3-5) describes recruitment as "those practices and activities carried on by the organisation with the primary purpose of identifying and attracting potential employees", and selection as those process that "aimed at identifying the most qualified from those" who applied for a job. According to Filip and Chapman (2009), recruitment and selection function has been regarded an old personnel management function, yet only few people question its potential in strategic HRM domain. The rapid shifts in the business environment of organisations maybe at odds with traditional recruitment and selection practices contributing to the view of recruitment and selection as an old personnel management function. It is suggested that organisations should be less dependent on traditional recruitment practices due to changes in the job market (Kessler et al., 2012). Technological changes are dramatically revolutionising the reconfiguration of recruitment and selection practices, making online recruitment and selection (computer-based) the default medium across organisations (Bartram, 2000; García-Izquierdoa et al., 2015). Indeed, computer-based assessment and selection is expected to drive recruitment and selection convergence among firms from both developed and less advanced countries across the globe. While traditional recruitment and selection practices may persist as an ideal medium for some organisations, social media technologies will trigger a shift from traditional recruitment and selection platforms to internet-based procedures (Selden \& Orenstein, 2011; Bartram, 2000). Though the growing accessibility of internet services will directly increase the utilisation of online recruitment and selection sources, job-seekers are also expected to find work via online platforms compared to traditional recruitment sources (Oostrom et al., 2013). The institute of employment studies found that $55 \%$ of organisations are expected to reduce the utilisation of traditional recruitment and selection procedures in favour of e-recruitment (see Kerin \& Kettley, 2003). The increasing use of internet technologies as a platform for testing and recruiting potential applicants has been underpinned by decrease in recruitment cost, administrative burden and support corporate image improvement (Thanassoulis et al., 2018; Kerin \& Kettley, 2003). The advancement in technology has provided a widespread availability of high-powered computer systems and internet services across the globe (Caers \& Castelyns, 2011). Therefore, the convergence towards a common recruitment and selection standard will be made possible with the availability of more sophisticated computer-based applications in the future.

\section{Multiple Case-study Design}


The HRM literature within the context of sub-Saharan African region is still at its embryonic stage though some significant progress has been made over the last few years. This paper is part of a set of studies that aim to explore HRM practices of Ghanaian firms. Even though case-study research design has been criticised for its lack of robustness, it remains an important component of management research and, especially HRM research (McAbee, Landis \& Burke, 2017; Yin, 2011). The correlation between case-study research design and good-theory building has been established within several epistemological studies. Therefore, a well-designed case-study research approach potentially contributes to management theory and practice (Collinson \& Rugman, 2010). The benefits of building theories from case-studies research have witnessed an increasing trend in its application in different research disciplines, particularly in the management domain (Collinson \& Rugman, 2010). In order to address the lack of robustness characterising single-case study designs, I triangulated the study by adopting a multiple-case design. Multiple-case design help advance the level of the study robustness (Yin, 2014). Identifying appropriate case-study organisations for organisational level studies, particularly in the HRM domain remain contentious. Organisational level studies literature points to the fact that firms with limited employees' size are likely to have undocumented HRM policies and programs. In addition, such firms are not able to engage the services of a qualified HRM manager to ensure the effective operationalisation of the HRM functions. The HRM literature thus argues in favour of selecting case organisations with a spread in company size in relation to employee size (Hill \& Stewart, 2000). This criterion governing the choice of case selection is underpinned by the assumption that firms with large employee size are more likely to have a well-structured HRM department and proper HRM policies and programs compared to small and medium size enterprises. Such firms are also likely to employ a qualified HRM manager to ensure the effective operationalisation of the HR department. Therefore, the case-study organisations selected for this study fall within an employment size of between 250 and 6500 employees.

The main approach for this paper was to draw on multiple case-study organisations as the primary source of data collection and complement that with secondary literature sources such as HRM manuals, newspapers, reports and information from the case organisations websites. This research strategy forms part of the data triangulation processes due to potential biases associated with organisational level studies that draws data from only key informants. Data triangulation further strengthens the validity and reliability of the study evidence (Yin, 2014). The first step was to establish contacts with officials from the Ghana Employers Association, as an important avenue to establish contacts with case study organisations. I was able to secure five case study contacts to conduct the fieldwork. These five case organisations were operating in different sectors and industries located in Tema, Kumasi and Accra, which are the three most important industrial park locations in Ghana. One important advantage of the five sample case organisations was that they provided a mix of complementary and contrasting evidence based on their mode of establishment (for example, joint venture, wholly-owned) and industry types (for example, manufacturing and services). These salient characteristics of the five case-study organisations add a further potential strength in multiple case-study research design (Yin, 2014). Given the detailed nature of case-study research and because the focus was to explore HRM practices of Ghanaian firms in detail, the participant selection was influenced by participants' information potential. Thus, the targeted interview participants were selected purposively and included HR managers, line managers and functional managers. I developed a semi-structured interview guide prior to the field work. The interviews were all audio-recorded and lasted between 45 to 60 munities each. All the interviews were conducted in English. The participants were given two weeks prior notice in addition to submitting consent and information sheets outlining the purpose and scope of the interviews. This approach was to give participants ample time to prepare for the interviews. For the purposes of anonymity, I used case numbers to represent the five case organisations, for example, Case \# 1, 2 up to 5. Below are detailed descriptions of the five cases. In all, thirty-two (32) interviews were conducted with top, middle and line managers within a period of three months.

Case \# 1 is one of the largest telecommunication firms with operations in Ghana and other parts of Africa. The company operates in all ten regions of Ghana with its head office located in Accra. The company is a joint-venture and employs over 5000 people in Ghana. The company provide internet, voice, fixed line, mobile and data services and has currently introduced mobile money services. The company is ranked second in Ghana in terms of market share or customer base in the telecommunication sector. The researcher interviewed seven key participants who were the Business Partners in-charge of human resource and employment relations management, line managers and functional managers. The key participants have been working in the same positions for over six years.

Case \#2 operates in the banking sector and was established in the mid-1970s as a security guarantee bank and was later rebranded, and converted into a public limited liability company. After few years, the bank was listed on the Ghana Stock Exchange. Today, the company has 45 branches across the ten regions of Ghana with its head office in Accra and employs over 1000 people. In 2013, the company rebranded to reflect the new ownership structure now bearing the name of the majority shareholder. The company is the 5th largest bank in Ghana by assets as at 2011, with a total asset of US\$ 554+ million and an annual revenue base of US\$15 million. The company provide both corporate and retail financial services to their clients. The researcher interviewed six key informants, the Business Partners responsible 
for recruitment and selection and training and the talent management and organisational development managers, line and functional managers.

Case \#3 is one of the major manufacturer of consumer goods and personal healthcare products in Ghana and other West African countries. It started its operations in the 1930s as an importer and distributor of consumer goods and healthcare products and later graduated into a manufacturing company in 1934, and currently employs about 6125 people. The company is also acknowledged as a pioneer to be listed on the Ghana Stock Exchange since its establishment in the early 1990s. The company has an annual revenue base of US\$300 million as at 2015 . The company is often associated with detergents and healthcare products as well as electronics and food and nutrition products. Eight key participants, that is, the Head of Human Resource who has been working with the firm for the past nine years, Senior HR Officers, line managers and functional managers were interviewed.

Case \#4 operates in all ten regions of Ghana with its head office located in Accra. The company provides internet, voice, fixed line, mobile, data services and mobile money services. The company is ranked third in terms of market share in the telecommunication industry in Ghana. The company is well known in Ghana through its mobile money services and is the pioneer for the introduction of the mobile money services and the platform for the payment of utility bills in Ghana. The company employs over 500 people. The researcher interviewed five key participants, including Junior Human Resource Officers and Senior Human Resource Officers who have been working in the company for over six years.

Case\# 5 is a joint venture company and has its production plant located in the Ashanti region (Kumasi) and a service centre located in Accra, the national capital. The company operates vehicle sales and vehicle services business activities. The company was established in December 1974 through "heads of agreement" between the government of Ghana and a German car manufacturing firm specialised assembling tropical busses. It became the first car manufacturing company to be located in Ghana to serve the whole West Africa Sub-region with tropical buses. In 2013, the German firm off loaded their shareholding to a Lebanese company. The company employs over 290 people. The researcher interviewed six key informants, including the acting HR manager, line manager and functional managers. The line manager has been working with the company for over fourteen years, whereas the acting HR manager has been working for over six years.

\subsection{Data Analysis}

Qualitative data analysis in a multiple case-study research is multifaceted and requires flexibility due to the large amount of data coming from multiple sources - interview transcripts, field notes and written documents. The data analysis was based on an ongoing clarification approach advocated by Yin (2014) in relation to case-study research design. Similarly, Evers and van Staa (2010, p.753) argued that "in qualitative case studies, data analysis consists of reduction and reconstruction in a continuous, ongoing process". I analysed and interpreted the data to reflect each case study outcomes and apply similarly across all the cases that account for the entire data set of the research. Given that sequence is very important, as information in one case must first have an explanatory power, I employed the thematic analysis technique. Thematic analytic technique offered the opportunity to immerse myself in the fieldwork data which enables me to organise and interpret the data within its context and by seeking commonalties, relationships, overarching patterns, theoretical constructs or explanatory principles (Lapadat, 2010). The thematic structures were also set by the literature prior to the data collection.

\section{Results}

The various evidence presented in this paper emerged from key participants responses in relation to recruitment and selection practices commonly used in their respective organisations as well as documentary records of their recruitment and selection practices. The evidence presented here specifically relates to the recruitment procedures and selection techniques.

Case \#1 - The Company uses different recruitment and selection practices for the different categories of employees managers, key employee group (KEG) and the largest occupational group (LOG). The participants define the largest occupational group to represent employees who do not require specialised skills, for instance, office and administrative support workers, call centre staff, whereas key employees group exemplify technical occupations, for example, engineers and managers represents heads of department and those occupying key and strategic positions such as marketing managers, HR managers, finance managers, etcetera. Recruitment practices such as newspaper advertisements and headhunting are generally used for the recruitment of managers and some key employee groups, especially key and strategic managerial positions. The company also use internal advertisements through the company intranet to advertise some key jobs. Employee referrals have also become a common practice, especially for the recruitment of managers and key employee groups. Participants indicated that in many instances, they have relied on managers and key employee 
group who have left the company to recommend any person they feel can replace them. According to the Business Partners in-charge of human resource, this approach has led to the successful recruitment of managers and key employee group into the company.

As a company one of the things we have set ourselves to do is that as much as possible we will recruit from within so anytime there is a vacancy, we advertise it within, we have our intranet, we advertise it there, so if we advertise the vacancy and we don't get anybody to fill in, then we look out, so by looking out we could advertise it in the mass media, the newspapers, sometimes in the company's website. So we advertise internally and externally

Participants also alluded to the fact that private recruitment firms are mostly engaged to recruit the largest occupational group including call centre agents, clerical staff and security officers. Another practice which is also used is campus recruitment of new university graduates. When it comes to employee selection, the same practices are applied for the selection of all the three categories of employees, except for those recruited through private recruitment firms which are the largest occupational group. Assessment centres, psychometric testing or aptitude testing, face-to-face interviews, curriculum vitae $(\mathrm{CV})$ data and references are used irrespective of the rank of the job vacancy in the company. The same selection practices are used for all the different category of employees (managers, Key employee and some few positions under the LOG). Poaching has also become a form of recruitment practice frequently used for sourcing managers and key employees where there is a shortage within the labour market.

When it comes to recruitment, we do it in two broad forms.... we have the standard recruitment process, as in the vacancy being advertised, people expressing their interest, going probably unto the hub and applying, getting shortlisted for the interview and sometimes going to do a presentation....

Another participant indicated that

If we realised that your skill or competency is one that we don't find in-house or which we advertised but are not getting, the other option that we use to get them is the poaching

Case \# 2 - There is variations in the use of recruitment methods among the three categories of employees for case \#2. The participants indicated that they rely extensively on newspaper advertisements, headhunting and private recruitment firms (outsourcing) for the recruitment of managers, whereas key employee group are recruited using direct application/unsolicited applications and private recruitment firms. With regards to the largest occupational group, especially entry level university graduates, they utilise campus recruitment, employee referrals, direct applications and unsolicited applications.

We use campus recruitment for entry level, for national service persons for instance after their service those who have performed well, we engaged them at the entry level, employee referrals, direct applications and unsolicited applications as well

In relation to the selection techniques, the company applies the same set of selection techniques for all the three categories of employees. The company uses application forms, assessment centres, CV data, face-to-face interviews and references in the selection of managers, key employee group and the largest occupational group.

Case \# 3 - The recruitment and selection practices also vary in case \# 3 according to the different categories of employees. The Company uses employee referrals, unsolicited applications, headhunting and private recruitment firms for the recruitment of managers and the key employee group. When it comes to the largest occupational group, private recruitment firms and employee referrals are the most commonly used recruitment practices. On the one hand, CV data, references and face-to-face interviews are the most frequently used selection techniques for the selection of all the three different employees' category.

We use the same procedure for the recruitment and selection of our employees...excerpt for some

few vacancies such as security, cleaners among others ... which we have outsourced to private recruitment firms

Case \# 4 - Recruitment of employees in the company varies in relation to the different categories of employees involved. With regards to the recruitment of managers and key employee group, the company adopt employee referrals, social media and headhunting recruitment practices, whereas the recruitment of the largest occupational group is frequently dependent on campus recruitment and in most cases outsourcing such class of recruitment to private recruitment firms.

We now have social media to advertise most of our managerial vacancies here, if we want to recruit fresh graduates as part of their national service, we go to the university campuses to do that

The company's selection processes also vary in relation to the category of employees being sourced. The company has developed a standard application form where it can be downloaded from the company's website. They also rely on CV 
data, face-to-face interviews and the use of aptitude testing for the selection of only managers and key employee group. In recent times, presentations have become an important part of the selection processes. Presentations are most often used for the recruitment of managers and some few key employee groups who will be heading some key and strategic positions in the company. Those applicants applying for managerial positions do a presentation of what they want to add or achieve for the company when given the opportunity. On the one hand, aptitude testing is frequently used for the recruitment of the largest occupational groups or entry level applicants and less utilised for the recruitment of managers and key employee groups. The company does not use assessment centres as part of its selection processes.

Case \# 5 - The Company's recruitment and selection practices vary across the different categories of employees. With regards to the recruitment of managers, newspaper advertisement is the main recruitment source, whereas the recruitment of key employee group is carried out through employee referrals and newspaper advertisement. The source of recruitment for the largest occupational group is mainly through employee referrals. When it comes to the selection techniques, the company uses written application letters by the employees themselves, face-to-face interviews, CV-data, references in selecting managers and key employee group. The largest occupational group selection technique is mainly based on recommendations from existing employees. According to one of the line manager of the company [we just rely on the people over there in Suame magazine because they are our old products, the moment there are chances here, their colleagues drop them a hint, they will bring them here and recommend them to the Personnel Officer, and we like them in a way that.... they had already worked here before, they have already got the experience, so when they come they don't cause any wastage compared to the recruitment of new employees who don't have any experience]. Because the company is already familiar with such applicants, they do not undergo any rigorous selection process, but they just undergo an orientation training program.

Another key participant said:

Employee referrals are prevalent at the LOG... for that one you won't hear that the company is doing anything, they will refer that ...... oh please we are doing recruitment here and they come from Magazine ......... through their own social network they will bring the people here

In case \# 5, another feature of their recruitment and selection practices is where the recruitment and selection of the managing director and production manager and strategic positions are carried out by the minority shareholders, that is from their parent company's headquarters in Germany, whereas the recruitment and selection of other categories of employees are carried out by the majority shareholder, which is the government of Ghana through the Ministry of Transport. These recruitment and selection processes are generally politically influenced and mostly do not follow any standardised procedure as expected.

\subsection{Comparing Results}

The results presented in this paper based on the five case study organisations have revealed more commonalities in the utilisation of the following employee recruitment sources - for instance, newspaper advertisement, campus recruitment, employee referrals, direct applications and unsolicited applications. The commonalities were also evident in the varied utilisation of the recruitment and selection practices for the different categories of employees being sourced. While headhunting represents an important recruitment approach, particularly for the recruitment of managers and key employee group in four case study organisations excerpt case \#5, employee referrals and outsourcing or the use of employment agencies was evident in the recruitment of the largest occupational groups. The results also revealed that the use of psychometric testing or aptitude testing also demonstrated some significant commonality despite the variations in its application among the five cases. For example, while in some cases, psychometric testing or aptitude testing were used in the recruitment of only managers and key employees, some cases such as case \# 4, psychometric testing or aptitude testing is only utilised for the recruitment of the largest occupational group. Case \# 3 and 5 failed to use psychometric testing or aptitude testing as part of the selection procedures. It is also fascinating to note that the use of assessment centres was only present in case \# 1 and case \# 2. Internet recruitment platforms were not fully utilised, only case \# 1 and case \# 4 advertise their job vacancies through their intranet and social media platforms, the rest of the case companies still relied on traditional recruitment sources. In conclusion, despite the evidence generally points to significant convergence in the utilisation of recruitment and selection practices, there exists some few variations in the application of the various recruitment and selection practices among the different categories of employees being sourced by the various case study organisations.

\section{Discussion and Implications}

This paper makes an important contribution to the growing recruitment and selection literature from under-represented HRM research contexts. The results have revealed significant convergence in the utilisation of the following employee recruitment sources - for example, newspaper advertisement, campus recruitment, employee referrals, direct 
applications and unsolicited applications. The paper lends significant support to the recruitment and selection literature, where Breaugh and Starke (2000) found newspaper advertisements, employment agencies, direct application, employee referrals and campus recruitment are commonly used recruitment sources among employers. The results provided evidence to demonstrate that employee referrals were also associated with formal jobs recruitment, especially the recruitment of managers and key employee groups as well as the largest occupational group contrary to Elliott (2001) who found insider referrals to be most often associated with informal jobs compared to formal jobs. The advancement in technology has provided a widespread availability of high-powered computer systems and internet services across the globe (Herdonson, 2018). Therefore, the convergence towards a common recruitment and selection standard will be made possible with the availability of more sophisticated computer-based applications. The results in this paper have suggested many instances of recruitment and selection practices commonalities (convergence) in relation to the different categories of employees (managers, KEG, LOG) being sourced by firms. Surprisingly, this convergence was rather driven by traditional recruitment and selection practices with limited evidence of digitally enabled recruitment and selection platforms. The utilisation of new and emerging technologies induced by technological advancement has led to the growing interest in internet-based recruitment and selection as a significant employee recruitment and selection platform among many organisations (Brandão et al., 2018). This interest has also been demonstrated by potential jobseekers preference for online recruitment platforms and the considerable growth in job-search, especially through social media websites by job-seekers (Brandão et al., 2018; Ouirdi et al., 2016a). It is important to acknowledge here that though digitally enabled recruitment platforms are growing significantly among organisations, yet the evidence in the paper rather demonstrates limited growing visibility towards digitally enabled recruitment platforms in Ghanaian organisations. For example, only case \#1 and case \# 4 relatively advertise jobs using internet-based platforms, whereas the rest of the cases predominantly rely on traditional recruitment sources. The results may not be surprising as access to technological infrastructure in Ghana and generally sub-Saharan Africa remains relatively low, thus restricting firms in the utilisation of digitally enabled recruitment platforms. This may be true due to the limited internet access, as firms are likely to limit their access to potential talents (skilled labour) with the use of digitally enabled recruitment platforms. Finally, digitally enabled recruitment platforms may remain relatively unknown among Ghanaian employers characterised by small and medium size enterprises, which contribute about 80 per cent of employment opportunities (Abor \& Quartey, 2010).

Within the current labour market, social media platforms such as Twitter, Facebook and LinkedIn have become popular among job-seekers and potential employers respectively (Henderson, 2018). The substantial growth in social media usage over the last few years, points to the future prospects of social media-based recruitment and selection owing to its associated benefits. The literature argues that social media-based job-seekers screening is associated with transparency, less administrative burden and time and also assist employers to access objective applicants' information, especially nonprofessional information not captured in resumes (Thanassoulis et al., 2018; Ouirdi et al., 2016b). Several professional surveys found popularity in the usage of social media in employee recruitment and selection to have increased significantly as many of the new hires have been screened via social media platforms over the last few years (Brandão et al., 2018). It is, therefore, surprising that with the increased popularity of digitally enabled recruitment platforms across the world, Ghanaian firms have not sought ways to benefit from these social media technologies in their recruitment and selection processes. For example, the literature also lend support to the argument that social mediabased screening gives employers supplementary information to evaluate job-seekers and maximise both person-job fit and person-organisation fit outcomes (Acikgoz, 2018; Ouirdi et al., 2016b). One practical implication is the need for Ghanaian firms to adopt digitally enabled recruitment platforms to improve both efficiency and effectiveness and also to reflect in the emerging changes in the workforce demographics who are technology savvy.

Despite the evidence generally points to significant convergence in the utilisation of recruitment and selection practices, there exists some few variations in the application of the various recruitment and selection practices among the different categories of employees being sourced by the various case-study organisations. These differences point to the different industry types, for example, it was only in case \#1, 2 and 4 operating in the services sector (Telecommunication and Finance) that utilised psychometric or aptitude testing as part of their selection procedures. Many of the participants from case \#1, 2 and 4 believed that due to the nature of services delivered, it was important to use psychometric testing system to ensure they attract the required employees with the right capabilities. Whereas, case-study organisations operating in the manufacturing sector, for instance, case \#3 and 5 did not demonstrate any utilisation of aptitude testing system as part of their selection procedures. The differences in the recruitment channels demonstrated between the various cases may lend support to the argument that the shortage of skilled labour varies from industry to industry contributing to the distinctions in the recruitment and selections strategies between specific job positions and industries (Posthumus, Bozer and Santora, 2018). Arguing through the lens of contingency theory, the researcher found HRM 
policies and strategies in organisations to be contingent on both internal and external contextual factors (Posthumus et al., 2018; Angrave et al., 2016). Thus, employee recruitment decisions are most likely to be made subject to firm-specific and industry conditions.

\section{Conclusion}

This paper set out a rationale for utilising multiple case-study design in HRM research in under-researched contexts. The discussion has centred on recruitment and selection practices engaged by Ghanaian firms. The paper points out to three different categories of employees which influence the nature and type of recruitment and selection processes to be followed. In drawing some conclusions, the results have revealed significant convergence in the utilisation of the following employee recruitment sources - example, newspaper advertisement, campus recruitment, employee referrals, direct applications and unsolicited applications. Despite the evidence generally points to significant convergence in the utilisation of recruitment and selection practices, there exists some few variations in the application of the various recruitment and selection practices among the different categories of employees being sourced by the various case-study organisations. It was also noted that though digitally enabled recruitment platforms are growing significantly among organisations, yet the evidence in the paper rather demonstrate limited growing visibility towards digitally enabled recruitment platforms in Ghanaian organisations.

\section{Direction for future research}

This paper identified several areas that need future research attention. First, the evidence points to little knowledge among Ghanaian firms on social media usage in employee recruitment and selection processes. Therefore, further research on the use of online recruitment and how job-seekers respond to online selection processes will contribute to the recruitment and selection literature. Second, even though over the last few years, social media-based recruitment has witnessed a significant increase, research is yet to determine the effectiveness of internet recruitment on organisational outcomes or in other words, the relationship between internet recruitment sources and employee survival rate or turnover (Zottoli \& Wanous, 2000). This, therefore, creates an important research niche within the recruitment and selection literature for further enquiry. Finally, empirical research on social media utilisation in employee recruitment and selection remains limited in the existing literature. This paper is limited to recruitment and selection practices in Ghanaian organisations; therefore, future research should consider other HR functions such as training and development, performance management, Compensation and Benefits, among others. It would be interesting if future research explores HR functions in private organisations and make comparison with public organisations to explore the similarities and differences.

\section{References}

Acikgoz, Y. (2018). Employee recruitment and job search: Towards a multi-level integration. Human Resource Management Review, doi.org/10.1016/j.hrmr.2018.02.009.

Ahmad, S., \& Schroeder, R. G. (2003). The impact of human resource management practices on operational performance: recognizing country and industry differences. Journal of Operations Management, 21(1), 19-43.

Angrave, D., Charlwood, A., Kirkpatrick, I., Lawrence, M., \& Stuart, M. (2016). HR and analytics: Why HR is set to fail the big data challenge. Human Resource Management Journal, 26(1), 1-11.

Ayentimi, D. T., Burgess, J., \& Brown, K. (2018). HRM practices of MNEs and domestic firms in Ghana: divergence or convergence? Personnel Review, 47(1), 2-21.

Ayentimi, D. T., Burgess, J., \& Dayaram, K. (2018). Does the historical and institutional re-construction of Ghana support the transfer of HRM practices? Journal of Management History.

Azungah, T., Michailova, S., \& Hutchings, K. (2018). Embracing localization: evidence from Western MNEs in Ghana. Cross Cultural \& Strategic Management.

Barber, A. E. (1998). Recruiting Employees: Individual and Organizational Perspectives. Sage, Thousand Oaks, CA.

Bartram, D. (2000). Internet Recruitment and Selection: Kissing Frogs to find Princes. International Journal of Selection and Assessment, 8(4), 261-274.

Boxall, P. (2018). The development of strategic HRM: reflections on a 30-year journey. Labour \& Industry: a journal of the social and economic relations of work, 28(1), 21-30.

Brandão, C., Silva, R., \& dos Santos, J. V. (2018). Online recruitment in Portugal: Theories and candidate profiles. Journal of Business Research, doi.org/10.1016/j.jbusres.2018.04.011

Breaugh, J. A. (2008). Employee recruitment: Current knowledge and important areas for future research. Human Resource Management Review, 18(3),103-118.

Breaugh, J. A., \& Starke, M. (2000). Research on Employee Recruitment: So Many Studies, So Many Remaining Questions. Journal of Management, 26(3), 405-434.

Brindusoiua, C. (2013). Recruitment and Selection in Services Organizations in Romania. Procedia - Social and Behavioral Sciences, 92, 112-116.

Caers, R., \& Castelyns, V. (2011). LinkedIn and Facebook in Belgium: The Influences and Biases of Social Network Sites in Recruitment and Selection Procedures. Social Science Computer Review, 29(4), 437-448.

Collings, D. G., Scullion, H., \& Morley, M. J. (2007). Changing Patterns of Global Staffing in the Multinational 
Enterprise: Challenges to the Conventional Expatriate Assignment and Emerging Alternatives. Journal of World Business, 42(2), 198-213.

Collinson, S., \& Rugman, A. M. (2010). Case selection biases in management research: the implications for international business studies. European Journal International Management, 4(5), 441-463.

Elliott, J. R. (2001). Referral Hiring and Ethnically Homogeneous Jobs: How Prevalent Is the Connection and for Whom? Social Science Research, 30(3), 401-425.

Filip, L., \& Chapman, D. (2009). Recruitment and Selection, in The SAGE Handbook of Human Resource Management, Wilkinson (Eds). Sage (pp.133-154)

Evers, J. C., \& van Staa, A. (2010). Qualitative Analysis in Case Study, in Encyclopedia of Case Study Research (Eds) Mills, A.J., Durepos, G. and Wiebe, E. Sage

García-Izquierdoa, A. L., Derous, E., \& Searle, R. (2013). Recruitment and Selection in Europe: One step beyond. Journal of Work and Organizational Psychology, 29, 1-2.

Gong, Y. (2003). Subsidiary staffing in multinational enterprises: Agency, resources, and performance. Academy of Management Journal, 46(6), 728-739.

Henderson, K. E. (2018). They posted what? Recruiter use of social media for selection. Organizational Dynamics, doi.org/10.1016/j.orgdyn.2018.05.005

Hill, R., \& Stewart, J. (2000). Human resource development in small organizations. Journal of European Industrial Training, 24(2/3/4), 105-117.

Kessler, R., Béchet, N., Roche, M., Torres-Moreno, J., \& El-Bèze, M. (2012). A hybrid approach to managing job offers and candidates. Information Processing and Management, 48(6), 1124-1135.

Lapadat, J. C. (2010). Thematic Analysis, in Encyclopedia of Case Study Research, Mills, A. J., Durepos, G. and Wiebe, E. (Eds). Sage

Ma, R., \& Allen, D. G. (2009). Recruiting across cultures: A value-based model of recruitment. Human Resource Management Review, 19(4), 334-346.

McAbee, S. T., Landis, R. S., \& Burke, M. I. (2017). Inductive reasoning: The promise of big data. Human Resource Management Review, 27(2), 277-290.

McFarland, L. A., \& Ployhart, R. E. (2015). Social media: A contextual framework to guide research and practice. Journal of Applied Psychology, 100(6), 1653-1677.

McManus, M. A., \& Ferguson, M. W. (2003). Biodata, Personality, and Demographic Differences of Recruits from Three Sources. International Journal of Selection and Assessment, 11(2/3), 175-183.

Morse, B. J., \& Popovich, P. M. (2009). Realistic recruitment practices in organizations: The potential benefits of generalized expectancy calibration. Human Resource Management Review, 19(1),1-8.

Oostrom, J. K., van der Linden, D., Born, M. P., \& van der Molen, H. T. (2013). New technology in personnel selection: How recruiter characteristics affect the adoption of new selection technology. Computers in Human Behavior, $29,2404-2415$.

Ouirdi, M. E., Ouirdi, A. E., Segers, J., \& Pais, I. (2016a). Technology adoption in employee recruitment: The case of social media in Central and Eastern Europe. Computers in Human Behavior, 57, 240-249.

Ouirdi, M. E., Pais, I., Segers, J., \& Ouirdi, A. E. (2016b). "The relationship between recruiter characteristics and applicant assessment on social media. Computers in Human Behavior, 62, 415-422.

Paauwe, J., \& Boselie, P. (2003). "Challenging 'strategic HRM' and the relevance of the institutional setting. Human Resource Management Journal, 13(3), 56-70.

Piotrowski, C., \& Armstrong, T. (2006). Current Recruitment and Selection Practices: A National Survey of Fortune 1000 Firms. North American Journal of Psychology, 8(3), 489-496.

Posthumus, J., Bozer, G., \& Santora, J. C. (2018). The use of market analytics in the recruitment of high potentials in the pharmaceutical industry. European Journal of International Management, doi: 10.1504/EJIM.2018.10014150.

Posthumus, J., Bozer, G., \& Santora, J. C. (2016). Implicit assumptions in high potentials recruitment. European Journal of Training and Development, 40(6), 430-445.

Rodgers, S., Stenhouse, R., McCreaddie, M., \& Small, P. (2013). Recruitment, selection and retention of nursing and midwifery students in Scottish Universities. Nurse Education Today, 33, 1301-1310.

Russell, S., \& Brannan, M. J. (2016). Getting the Right People on the Bus": Recruitment, selection and integration for the branded organization. European Management Journal, 34, 114-124.

Selden, S., \& Orenstein, J. (2011). Government e-recruiting web sites: The influence of e recruitment content and usability on recruiting and hiring outcomes in US state governments. International Journal of Selection and Assessment, 19, 31-40

Tangaa, M., \& Maphosa, C. (2018). Exploring the recruitment and training of peer facilitators in a South African University. International Journal of Educational Development, 61, 196-203.

Thanassoulis, E., Sotiros, D., Koronakos, G., \& Despotis, D. (2018). Assessing the cost effectiveness of university academic recruitment and promotion policies. European Journal of Operational Research, 264, 742-755.

Yin. R. K. (2014). Case Study Research: Design and Methods. Thousand Oaks, CA: Sage.

Yin, R. K. (2011). Applications of case study research: Sage.

Zottoli, M. A., \& Wanous, J. P. (2000). Recruitment source research: Current status and future directions. Human Resource Management Review, 10(4), 353-382. 